\title{
Melanocortin Antagonists Define Two Distinct Pathways of Cardiovascular Control by $\alpha$ - and $\gamma$-Melanocyte-Stimulating Hormones
}

\author{
Si-Jia Li, ${ }^{1}$ Károly Varga, ${ }^{1}$ Phillip Archer, ${ }^{1}$ Victor J. Hruby, ${ }^{2}$ Shubh D. Sharma, ${ }^{2}$ Robert A. Kesterson, ${ }^{3}$ \\ Roger D. Cone, ${ }^{3}$ and George Kunos ${ }^{1}$ \\ 1Department of Pharmacology and Toxicology, Virginia Commonwealth University, Richmond, Virginia 23298-0613, \\ ${ }^{2}$ Department of Chemistry, University of Arizona, Tucson, Arizona 85721, and ${ }^{3}$ Vollum Institute, Oregon Health Sciences \\ University, Portland, Oregon 97210
}

\begin{abstract}
Melanocortin peptides and at least two subtypes of melanocortin receptors (MC3-R and MC4-R) are present in brain regions involved in cardiovascular regulation. In urethaneanesthetized rats, unilateral microinjection of $\alpha$-melanocytestimulating hormone (MSH) into the medullary dorsal-vagal complex (DVC) causes dose-dependent (125-250 pmol) hypotension and bradycardia, whereas $\gamma-\mathrm{MSH}$ is less effective. The effects of $\alpha-\mathrm{MSH}$ are inhibited by microinjection to the same site of the novel MC4-R/MC3-R antagonist SHU9119 (2-100 pmol) but not naloxone $(270 \mathrm{pmol})$, whereas the similar effects of intra-DVC injection of $\beta$-endorphin ( $1 \mathrm{pmol}$ ) are inhibited by naloxone and not by SHU9119. Hypotensive and bradycardic responses to electrical stimulation of the arcuate nucleus also are inhibited by ipsilateral intra-DVC microinjection of SHU9119. $\gamma-\mathrm{MSH}$ and $\mathrm{ACTH}(4-10)$, but not $\alpha$-MSH, elicit dose-dependent $(0.1-12.5 \mathrm{nmol})$ pressor and tachycardic effects, which are much more pronounced after
\end{abstract}

intracarotid than after intravenous administration. The effects of $\gamma$-MSH $(1.25 \mathrm{nmol})$ are not inhibited by the intracarotid injection of SHU9119 (1.25-12.5 nmol) or the novel MC3-R antagonist SHU9005 (1.25-12.5 nmol). We conclude that the hypotension and bradycardia elicited by the release of $\alpha$-MSH from arcuate neurons is mediated by neural melanocortin receptors (MC4-R/MC3-R) located in the DVC, whereas the similar effects of $\beta$-endorphin, a peptide derived from the same precursor, are mediated by opiate receptors at the same site. In contrast, neither MC3-R nor MC4-R is involved in the centrally mediated pressor and tachycardic actions of $\gamma-\mathrm{MSH}$, which, likely, are mediated by an as yet unidentified receptor.

Key words: melanocortin receptors; blood pressure; heart rate; melanocortin antagonists; dorsal-vagal complex; $\alpha-M S H$; $\gamma-\mathrm{MSH}$
The melanocortins, melanocyte-stimulating hormone (MSH) and adrenocorticotropic hormone (ACTH) derived from the common precursor pro-opiomelanocortin (POMC), affect skin pigmentation and stimulate the adrenal cortex via the $\mathrm{MSH}$ receptor (MC1-R) expressed in melanocytes and the ACTH receptor (MC2-R) expressed in the adrenal cortex, respectively (Mountjoy et al., 1992). In addition to blood-borne ACTH and MSH produced in the pituitary, melanocortin peptides also are expressed in the brain, in the hypothalamic arcuate nucleus (Jacobowitz and O'Donohue, 1978; Bloom et al., 1980; Osamura et al., 1982; Umegaki et al., 1983), and in the dorsal medullary nucleus of the solitary tract ("nucleus tractus solitarii," NTS; Kawai et al., 1984; Yamazoe et al., 1984; Joseph et al., 1985). However, the physiological role of melanocortins in the brain is not well understood. The well documented behavioral effects of melanocortins (Wiegant et al., 1979; De Wied and Jolles, 1982) have long suggested the existence of additional receptor sites in the brain. Indeed, three additional melanocortin receptors recently have been cloned, two of which are expressed primarily in the brain: the

\footnotetext{
Received April 11, 1996; revised May 24, 1996; accepted May 30, 1996.

This work was supported by National Institutes of Health Grants HL-49938 to G.K., DK-17420 to V.J.H., and HD-30236 to R.D.C.

Correspondence should be addressed to Dr. George Kunos, Department of Pharmacology and Toxicology, Virginia Commonwealth University, Box 980613, Richmond, VA 23298.

Copyright (C) 1996 Society for Neuroscience $0270-6474 / 96 / 165182-07 \$ 05.00 / 0$
}

MC4-R (Gantz et al., 1993), which is widely distributed in the brain and has high affinity for $\alpha$-MSH and low affinity for $\gamma$-MSH (Mountjoy et al., 1994), and the MC3-R, which is limited to the arcuate nucleus and some of its projection fields and has high affinity for both $\alpha$-MSH and $\gamma$-MSH (Roselli-Rehfuss et al., 1993). The highest concentration of MC4-R mRNA is found in the medullary dorsal-vagal complex (DVC), an area that includes the dorsal motor nucleus of the vagus and the NTS, which suggests that MC4-R may be involved in central cardiovascular control (Mountjoy et al., 1994).

The DVC is the site of the first synapse of the baroreceptor reflex, and it is also the termination point of POMC-containing neurons descending from the arcuate nucleus (Palkovits and Eskay, 1987; Sim and Joseph, 1991). Earlier studies have established that activation of POMC-containing neurons in the arcuate nucleus causes hypotension and bradycardia via the release of $\beta$-endorphin and subsequent activation of opiate receptors in the medullary DVC (Mosqueda-Garcia et al., 1986; Mastrianni et al., 1989) and that this pathway may be involved in the action of certain centrally acting antihypertensive agents (Kunos et al., 1981; Van Giersbergen et al., 1989; Li et al., 1996). The hypotension and bradycardia elicited by electrical stimulation of the arcuate nucleus were eliminated by ipsilateral deafferentation of the DVC but were inhibited only partially by intra-DVC microinjection of naloxone or a $\beta$-endorphin antiserum (Mastrianni et al., 1989). These findings suggest that $\beta$-endorphin may be respon- 
Table 1. Hypotensive and bradycardic effects of $\alpha$-MSH and $\gamma$-MSH microinjected into the DVC of anesthetized rats

\begin{tabular}{lccll} 
& \multicolumn{3}{c}{$\Delta \mathrm{BP}(\mathrm{mmHg})$} & $\Delta \mathrm{HR}($ beats $/ \mathrm{min})$ \\
\hline A) $\alpha$-MSH & $125 \mathrm{pmol}$ & $-14.0 \pm 3.1^{*}$ & $-42.0 \pm 7.3^{*}$ & $\mathrm{n}=5$ \\
& $250 \mathrm{pmol}$ & $-29.4 \pm 5.6^{*}$ & $-54.0 \pm 12.0^{*}$ & $\mathrm{n}=5$ \\
B) $\gamma$-MSH & $125 \mathrm{pmol}$ & $-7.2 \pm 3.5$ & $-13.5 \pm 1.5^{*}$ & $\mathrm{n}=3$ \\
& $250 \mathrm{pmol}$ & $-6.7 \pm 2.7$ & $-32.7 \pm 7.2^{*}$ & $\mathrm{n}=6$
\end{tabular}

$\overline{\text { Values represent peak changes from pre-injection basal BP and HR.*, Significant }}$ change from baseline value $(p<0.05)$.

sible for only part of these effects and that additional nonopiate mechanisms also are involved. Here we present evidence that $\alpha$-MSH and $\beta$-endorphin, both derived from POMC, cause similar hypotensive and bradycardic effects in the DVC by interacting with distinct melanocortin and opiate receptors, respectively, and that both types of receptor can be activated neurally from the arcuate nucleus. We further show that the centrally mediated pressor and tachycardic effects of $\gamma$-MSH do not seem to involve the MC3-R or the MC4-R.

\section{MATERIALS AND METHODS}

Adult male Sprague-Dawley rats (300-350 gm) were anesthetized with urethane, $0.7 \mathrm{gm} / \mathrm{kg}$ intravenously plus $0.3 \mathrm{gm} / \mathrm{kg}$ intraperitoneally. Urethane administered according to this protocol was found to produce stable and long-lasting anesthesia without causing hypotension or interfering with cardiovascular reflexes (Maggi and Meli, 1986). Drugs were injected via cannulae in the saphenous vein and the carotid artery, as indicated. Phasic and mean arterial blood pressure and heart rate were monitored via a cannula in the femoral artery connected to a pressure transducer and physiograph (Astro-Med, West Warwick, RI). Heart rate was derived by a tachograph preamplifier driven by the pressure wave. For intra-DVC microinjections, the head of the animal was fixed in a stereotaxic frame, the dorsal surface of the medulla was exposed by limited craniotomy, and a glass microcannula was inserted into the NTS by using the coordinates $0.0 \mathrm{~mm}$ (anterior/posterior), $+0.5 \mathrm{~mm}$ (medial/ lateral), and $-0.4 \mathrm{~mm}$ (dorsal/ventral) with the obex as reference (Mastrianni et al., 1989). Proper positioning of the microcannula was verified by dye injection and postmortem microscopy and by the hypotensive and bradycardic effects of a test dose of 1 nmol of glutamate. Unilateral insertion of a bipolar, concentric, stainless steel microelectrode into the arcuate nucleus and electrical stimulation were done as described (Mastrianni et al., 1989).

Drugs were dissolved in saline [ $\alpha$-MSH, $\gamma$-MSH, and $\mathrm{ACTH}(4-10)]$ or $0.5 \%$ methanol in saline (SHU9119) and microinjected in a volume of 50 $\mathrm{nl}$. Microinjection of vehicle had no effect on blood pressure or heart rate. $\gamma_{2}-\mathrm{MSH}$, acetylated $\alpha-\mathrm{MSH}$, and $\mathrm{ACTH}(4-10)$ were obtained from Bachem California (Torrence, CA); $\beta$-endorphin was obtained from Sigma (St. Louis, MO). SHU9119 (Ac-Nle ${ }^{4}-\mathrm{c}\left[\mathrm{Asp}^{5}, \mathrm{D}-\mathrm{Nal}(2)^{7}, \mathrm{Lys}^{10}\right] \alpha-$ MSH-(4-10)- $\mathrm{NH}_{2}$ ) and SHU9005 (Ac-[Nle $\left.{ }^{4}, \mathrm{D}-\mathrm{Phe}(\mathrm{pI})^{7}, \mathrm{Lys}^{10}\right] \alpha-\mathrm{MSH}-$ (1-13) $-\mathrm{NH}_{2}$ ) were synthesized by one of us (S.D.S.). Other drugs were from usual commercial sources.

Time-dependent changes in blood pressure and heart rate in response to an agonist in the absence or presence of an antagonist were compared by two-way ANOVA followed by Tukey's post hoc test. For comparing the peak response to stimulation in the absence or presence of an antagonist in the same animal, the paired $t$ test was used. Differences with a $p<0.05$ were considered statistically significant.

\section{RESULTS}

\section{Depressor and bradycardic effects of $\alpha$-MSH in the DVC}

In urethane-anesthetized rats, unilateral intra-DVC injections of $\alpha$-MSH (125-250 pmol/50 nl) caused dose-dependent decreases in mean arterial pressure and heart rate (Table 1), which peaked within 5-10 min (Fig. 1). The effects were long-lasting, with a return to baseline values in 60-80 min for the highest dose tested. Intra-DVC microinjections of $\gamma$-MSH in the same doses caused no significant change in blood pressure and a reduction in heart rate smaller than that seen after $\alpha$-MSH (Table 1). In separate animals, the effect of $250 \mathrm{pmol}$ of $\alpha$-MSH microinjected into the DVC was tested $10 \mathrm{~min}$ after the similar microinjection of 270 pmol of $l$-naloxone into the same site (Fig. 1B). This dose of $l$-naloxone was found, in an earlier study, to cause near-maximal inhibition of the effects of $\beta$-endorphin microinjected into the DVC of anesthetized rats (Mosqueda-Garcia and Kunos, 1987). $l$-Naloxone did not modify the effects of $\alpha$-MSH, indicating the lack of opiate receptor involvement.

In yet another group of rats, the effects of $250 \mathrm{pmol}$ of $\alpha$-MSH were tested after the intra-DVC microinjection of $10 \mathrm{pmol}$ of the compound SHU9119. In a recent study using cells transfected with various cloned melanocortin receptors (Hruby et al., 1995), SHU9119 was found to be a highly potent competitive antagonist of human MC4-R ( $\left.\mathrm{pA}_{2}, 9.3\right)$ with minimal agonist activity, a somewhat less potent antagonist of human MC3-R $\left(\mathrm{pA}_{2}, 8.3\right)$ with partial agonist activity, and a full agonist at the human MC1-R and the mouse MC5-R. In cells transfected with the rat MC3-R, SHU9119 had a $\mathrm{pA}_{2}$ of 8.5 and an activity profile similar to that in human MC3-R (R. A. Kesterson and R. D. Cone, unpublished data). Intra-DVC microinjection of 10 pmol of SHU9119 alone did not influence basal blood pressure and heart rate $(-2.6 \pm 1.0$ $\mathrm{mmHg}$ and $-3 \pm 8$ beats/min), but it markedly reduced the effects of subsequently microinjected $\alpha$-MSH (Fig. $1 A$ ). When in two experiments SHU9119 was used at a 10 times higher dose (100 pmol), it completely blocked the effects of $250 \mathrm{pmol}$ of $\alpha$-MSH microinjected into the same site (peak response to $\alpha-\mathrm{MSH},-1$ and $-5 \mathrm{mmHg}$ and -5 and +5 beats $/ \mathrm{min}$ ), whereas in two other experiments a lower dose of SHU9119 (2 pmol) reduced the maximal hypotensive response to $\alpha$-MSH by only $25 \%$ ( -12 and $-18 \mathrm{mmHg})$ and the bradycardia by $10 \%(-30$ and -43 beats/min).

In agreement with published observations (Petty and De Jong, 1982; Mosqueda-Garcia and Kunos, 1987; Li et al., 1996), unilateral microinjection of $1 \mathrm{pmol}$ of $\beta$-endorphin into the DVC also caused long-lasting hypotension and bradycardia (Fig. 2). Interestingly, the hypotensive response to $\beta$-endorphin developed slower than the similar effect of $\alpha$-MSH, reaching its peak only after 30-40 min, and recovery to baseline values took 90-120 min. In contrast to the effects of $\alpha-\mathrm{MSH}$, the responses to $\beta$-endorphin were not affected significantly by 10 pmol of SHU9119 (Fig. 2B) but were blocked completely by 270 pmol of l-naloxone (Fig. $2 A$ ).

Arcuate neurons projecting to the DVC contain both $\beta$-endorphin and $\alpha$-MSH (Palkovits et al., 1987). In earlier experiments, the hypotensive and bradycardic responses elicited by electrical stimulation of the arcuate nucleus were partially inhibited by microinjection of naloxone or a $\beta$-endorphin antiserum into the ipsilateral DVC (Mastrianni et al., 1989). We tested the effects of electrical stimulation of the arcuate nucleus before and after the bilateral intra-DVC microinjection of $10 \mathrm{pmol}$ of SHU9119. As illustrated in Figure 3, electrical stimulation of the arcuate nucleus caused a biphasic, depressor/pressor response and prolonged bradycardia. SHU9119 caused a small but significant reduction in the hypotension and a more pronounced inhibition of the bradycardia elicited by electrical stimulation of the arcuate nucleus. In four experiments, the stimulation-induced maximal decreases of blood pressure and heart rate were $-19 \pm 4 \mathrm{mmHg}$ and $-25 \pm 7$ beats/min before and $-13 \pm 3 \mathrm{mmHg}(p<0.05)$ and $-9 \pm 3$ beats $/ \min (p<0.01)$ after the bilateral intra-DVC microinjection of 10 pmol of SHU9119. The secondary rise in 


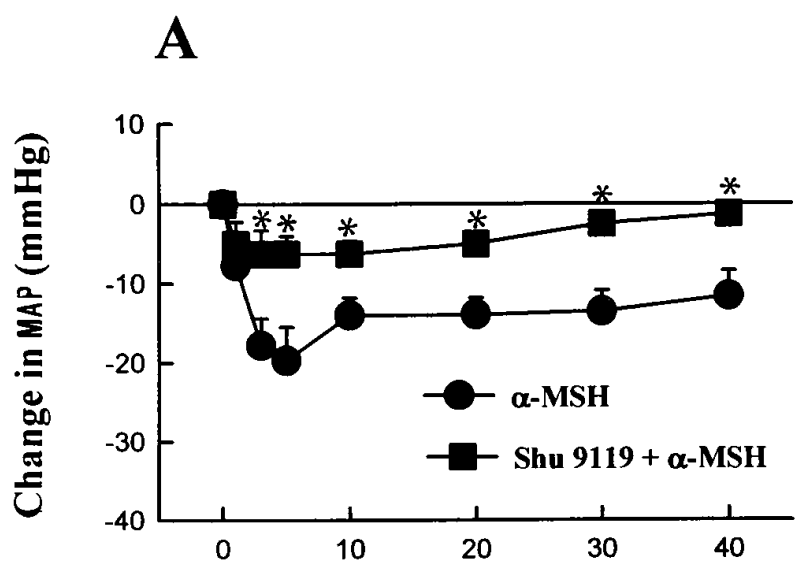

\section{B}
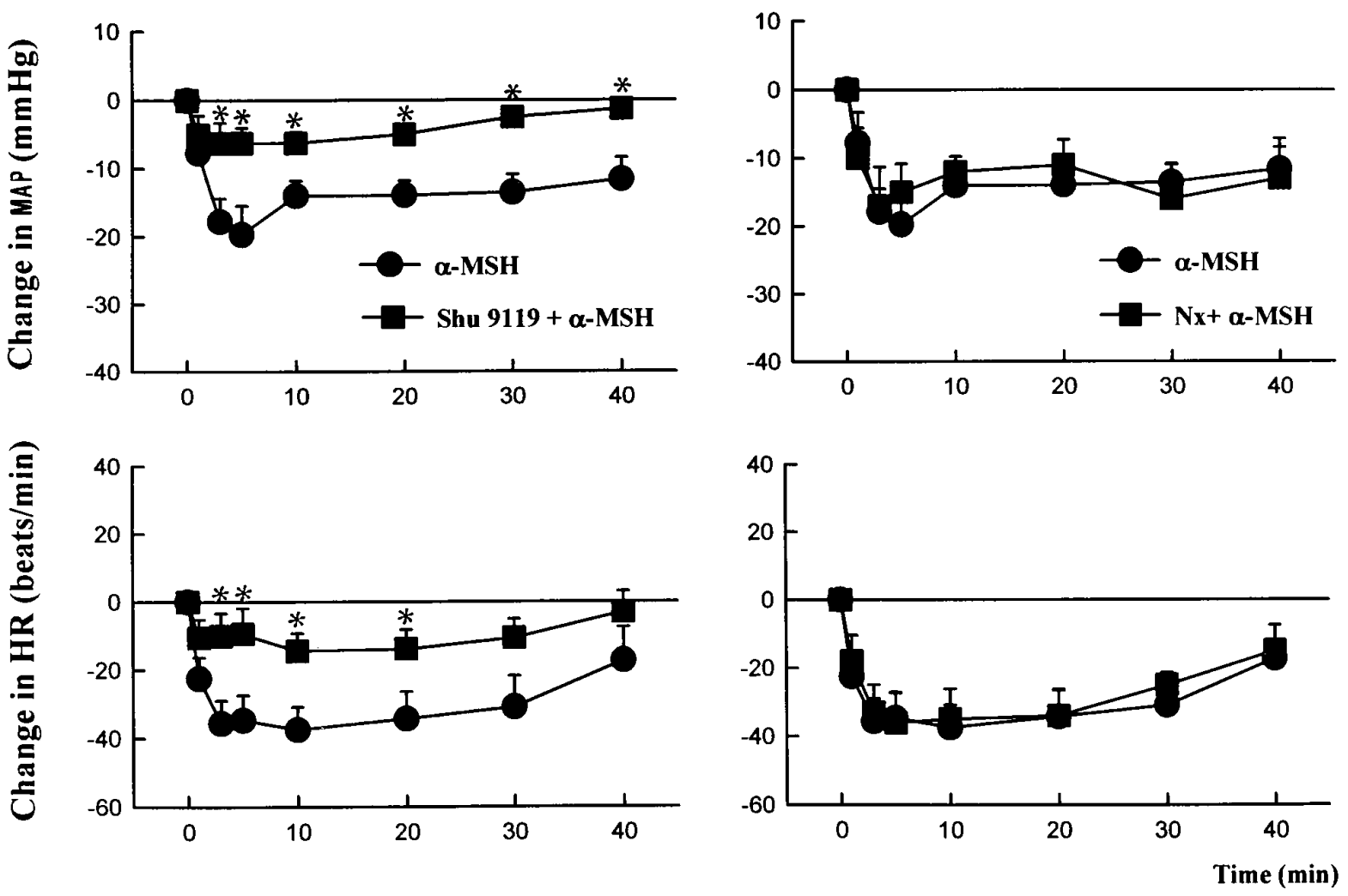

Figure 1. $\alpha$-MSH-induced hypotension and bradycardia are inhibited by SHU9119 but not by naloxone. $\alpha$-MSH (250 pmol/50 nl) was microinjected unilaterally into the DVC of urethane-anesthetized control rats ( filled circles) or rats that had received 10 pmol of SHU9119 (A) or 270 pmol of $l$-naloxone (B) microinjected into the same site $10 \mathrm{~min}$ before $\alpha$-MSH ( filled squares). Vertical bars, SE. There were 5-7 animals in each of the four different treatment groups. *, Significant difference $(p<0.05)$ from corresponding control value.

blood pressure that followed the stimulation was similar to that reported earlier by our own (Mastrianni et al., 1989) and another laboratory (Brody et al., 1986) and was not affected significantly by SHU9119. This latter effect has been attributed to vasopressin released via activation of an arcuate/paraventricular nucleus/posterior pituitary pathway (Brody et al., 1986; Mastrianni et al., 1989). The depressor and bradycardic components and their inhibition by SHU9119 are interpreted to indicate that activation of arcuate neurons projecting to the ipsilateral DVC releases not only $\beta$-endorphin (Mastrianni et al., 1989) but also $\alpha$-MSH and that both peptides contribute to the observed hypotensive and bradycardic effects by acting via distinct opiate and melanocortin receptors, respectively.

\section{Centrally mediated pressor and tachycardic effects of $\gamma$-MSH}

In urethane-anesthetized rats, intravenous injection of $1.25 \mathrm{nmol}$ of $\gamma$-MSH had no effect on blood pressure or heart rate, whereas $12.5 \mathrm{nmol}$ of $\gamma$-MSH caused a modest pressor response (Fig. 4). However, when injected into the carotid artery, a dose of 1.25 nmol of $\gamma$-MSH elicited a marked pressor effect $(44 \pm 3 \mathrm{mmHg})$ and tachycardia $(+25 \pm 3$ beats/min), and doses as low as 0.125 nmol caused similar but smaller effects (Fig. 4) that lasted 2-3 min. Similar but smaller pressor and tachycardic effects were observed after the intracarotid injections of $\mathrm{ACTH}(4-10)$, a peptide with very low affinity for MC3-R or MC4-R (Adan et al., 1994), whereas intracarotid injections of $\alpha$-MSH in doses up to
12.5 nmol caused no change in blood pressure or heart rate (Fig. 4). The effects of $1.25 \mathrm{nmol}$ of $\gamma$-MSH remained unchanged when retested after the intracarotid injection of $1.25 \mathrm{nmol}$ of SHU9119 $(+46 \pm 3 \mathrm{mmHg},+29 \pm 7$ beats $/ \mathrm{min} ; n=5)$ or $1.25 \mathrm{nmol}$ of SHU9005 $(+37 \pm 4 \mathrm{mmHg},+18 \pm 4$ beats/min; $n=5)$, the antagonists alone causing no change in blood pressure or heart rate. A 10 times higher dose of the antagonists similarly failed to inhibit significantly the effects of $\gamma-\mathrm{MSH}$; the pressor and tachycardic response to $1.25 \mathrm{nmol}$ of $\gamma-\mathrm{MSH}$ were +55 versus +50 $\mathrm{mmHg}$ and +20 versus +25 beats/min before versus after 12.5 nmol of SHU9119 $(n=2)$. The corresponding values before and after $12.5 \mathrm{nmol}$ of SHU9005 were $+43 \pm 7$ versus $+38 \pm 8 \mathrm{mmHg}$ and $+35 \pm 12$ versus $+27 \pm 13$ beats/min, respectively (mean \pm SE; $n=3$ ). SHU9005 is a novel, potent antagonist of the cloned, transfected rat MC3-R $\left(\mathrm{pA}_{2}, 8.6\right)$ and a full agonist at the cloned human MC4-R (EC50, $4.7 \times 10^{-10} \mathrm{M}$; Kesterson and Cone, unpublished observations). In agreement with published findings (Callahan et al., 1985), the $\alpha_{1}$-adrenergic receptor antagonist prazosin, $0.1 \mathrm{mg} / \mathrm{kg}$ intravenously, inhibited the pressor response, whereas the $\beta$-blocker propranolol, $1 \mathrm{mg} / \mathrm{kg}$ intravenously, inhibited the tachycardia elicited by $\gamma$-MSH (data not shown).

\section{DISCUSSION}

The present findings demonstrate that $\alpha$-MSH can cause hypotension and bradycardia by interacting with distinct melanocortin receptors in the medullary NTS. Of the three melano- 
A
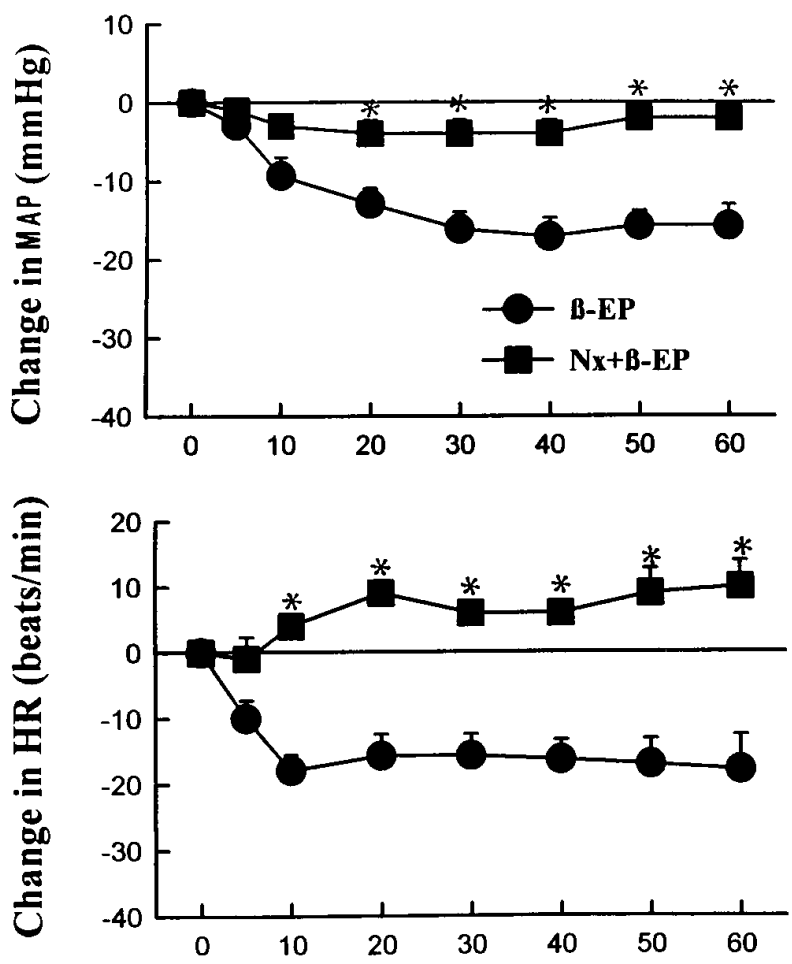

B
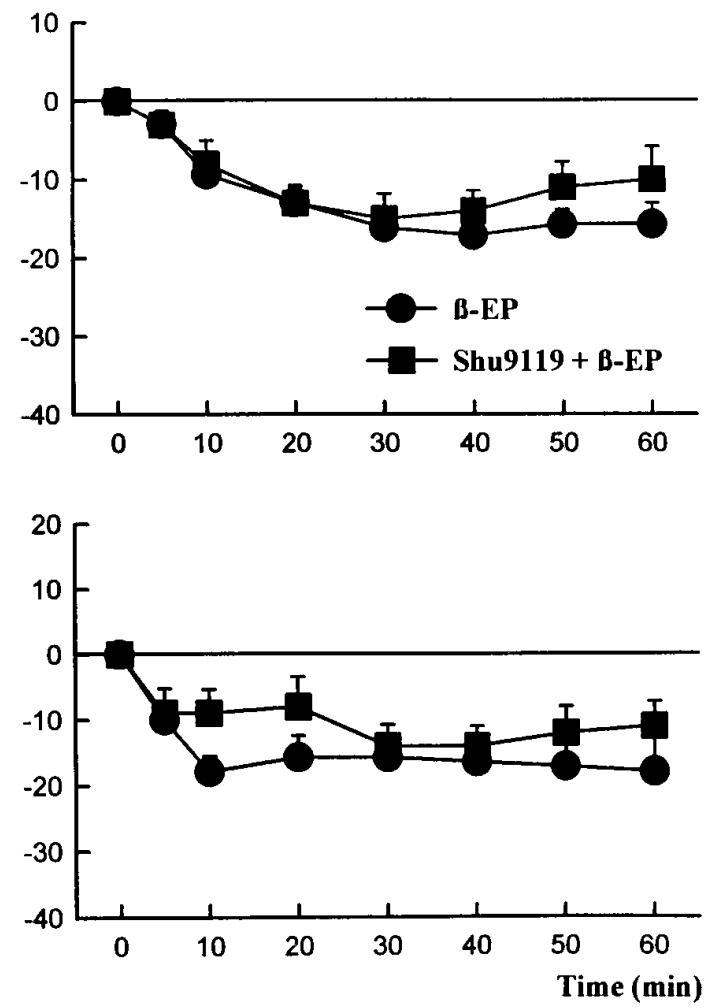

Figure 2. $\beta$-Endorphin-induced hypotension and bradycardia are inhibited by naloxone but not by SHU9119. $\beta$-Endorphin (1 pmol/50 nl) was microinjected unilaterally into the DVC in control rats ( filled circles) or in rats pretreated with 270 pmol of $l$-naloxone $(A)$ or 10 pmol of SHU9119 $(B)$ microinjected into the same site 10 min before $\beta$-endorphin ( filled squares). Vertical bars, SE. Each treatment group contained 5-6 animals. *, Significant difference $(p<0.05)$ from the corresponding control value.

cortin receptors expressed in the brain, the involvement of MC5-R is unlikely, as the level of the mRNA for this receptor is extremely low in the rat brain (Griffon et al., 1994), and SHU9119 is a highly potent full agonist at the MC5-R (Hruby et al., 1995), yet it produced no change in cardiovascular parameters when microinjected into the DVC. Of the other two neural melanocortin receptors, MC4-R has lower affinity for $\gamma$-MSH than for $\alpha$-MSH (Mountjoy et al., 1994), whereas the two peptides are equieffective at the MC3-R (Roselli-Rehfuss et al., 1993). Thus, the greater hypotensive and bradycardic potency of $\alpha$-versus $\gamma$-MSH and the ability of a very low dose of SHU9119 to inhibit these effects would favor the involvement of MC4-R over MC3-R. However, because of the limited selectivity of SHU9119 for these two receptors, we cannot exclude the additional involvement of MC3-R, which also could account for the more pronounced bradycardic action of $\gamma$-MSH, as reported in one recent study (De Wildt et al., 1994). In situ hybridization studies in the rat brain indicate that the DVC represents the area with the highest concentrations of MC4-R mRNA (Mountjoy et al., 1994), whereas MC3-R mRNA is absent from the DVC (Roselli-Rehfuss et al., 1993). However, this does not exclude the possibility that the very high levels of melanocortin receptors detected in the DVC by receptor autoradiography (Tatro and Entwistle, 1993) also include MC3-R present on terminal projections of neurons located elsewhere in the brain. Therefore, what one can confidently conclude from these findings is that the cardiovascular depressor effects of melanotropins are mediated by
MC4-R in the DVC with the possible additional involvement of $\mathrm{MC} 3-\mathrm{R}$, and the role of opiate receptors in these effects definitely can be excluded (Fig. $2 B$ ).

The finding that SHU9119 also inhibited the hypotensive and bradycardic response to electrical stimulation of the arcuate nucleus (Fig. 3) further suggests that MC4-R/MC3-R in the DVC can be activated neurally by $\alpha$-MSH found at high concentrations in the NTS region (Jacobowitz and O'Donohue, 1978; Palkovits et al., 1987). This possibility may seem at odds with the much greater potency of $\beta$-endorphin as compared with $\alpha$-MSH, as seen in Figures 1 and 2 . However, there is evidence for preferential processing of POMC into $\alpha$-MSH in the hypothalamus with $\alpha$-MSH/ $\beta$-endorphin ratios of 4:1 to 15:1 (Mezey et al., 1985). Furthermore, these ratios tend to increase further from perikarya to regions containing axonal projections (Mezey at al., 1985), compatible with the proposal of additional processing during axonal transport (Barnea et al., 1981). Thus, the lower potency of $\alpha$-MSH may be compensated by its greater abundance at the sites of release. Also, the hypotensive response to $\beta$-endorphin develops much slower than that of $\alpha$-MSH (see Figs. 1, 2), which would allow a greater contribution of $\alpha-\mathrm{MSH}$ in the early stage of the response. Another intriguing feature of POMC peptides is that the behavioral activity of $\beta$-endorphin is decreased and that of $\alpha$-MSH increased by acetylation (O'Donohue et al., 1982). Thus, one might speculate that the relative contributions to the net response of $\alpha$-MSH and $\beta$-endorphin released from the same neuron may be regulated by the activity of an opiomelanocortin acetylase. 
A

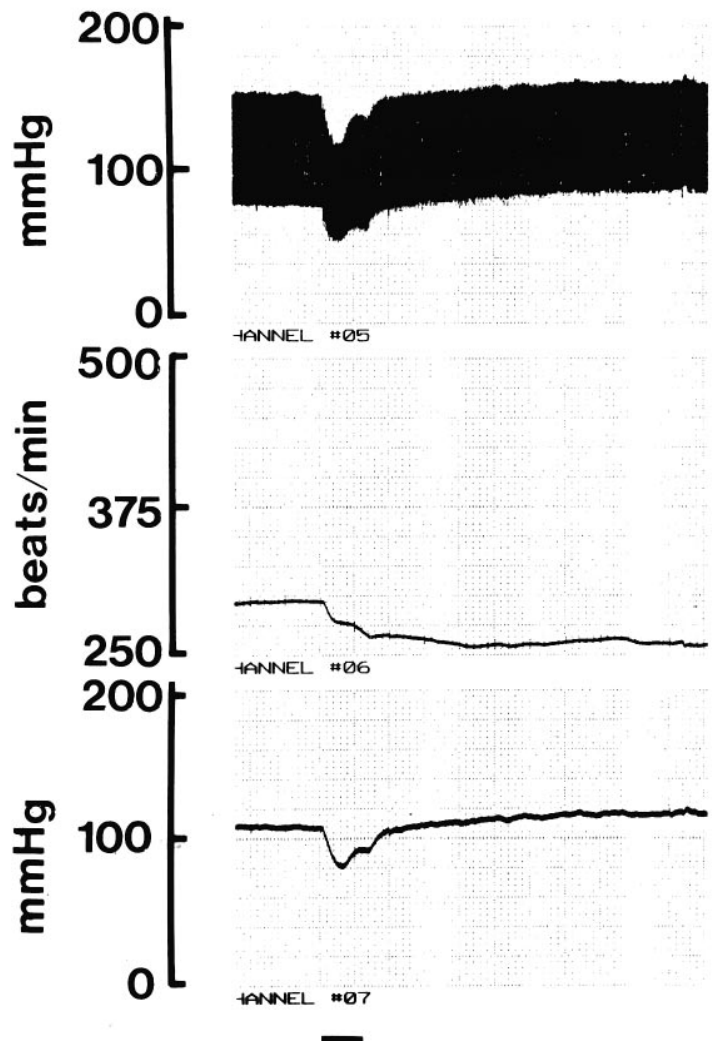

B

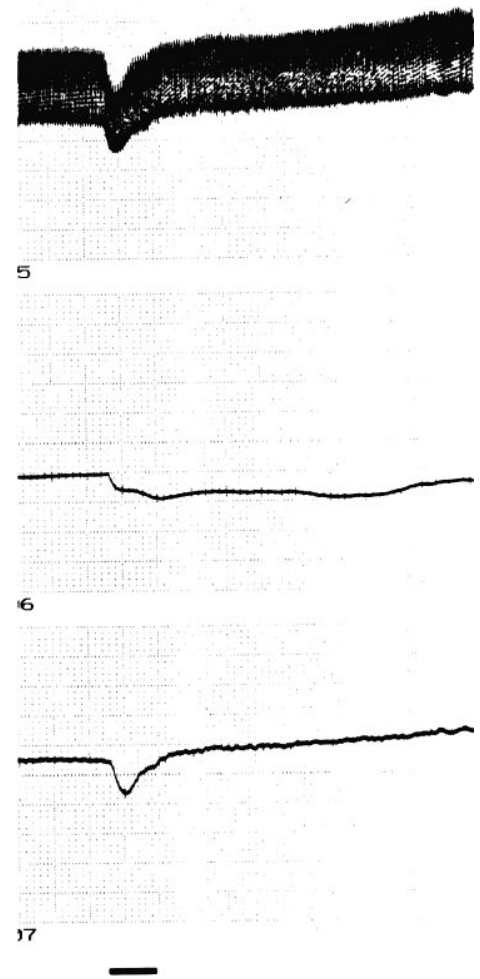

Figure 3. SHU9119 inhibits the hypotensive and bradycardic responses to electrical stimulation of the arcuate nucleus. The arcuate nucleus was stimulated unilaterally in a urethane-anesthetized rat via a stainless steel microelectrode at $100 \mu \mathrm{A}$, $0.8 \mathrm{msec}, 80 \mathrm{~Hz}$ for $15 \mathrm{sec}$ (horizontal lines) before $(A)$ and 10 min after $(B)$ the bilateral microinjection of $100 \mathrm{pmol}$ of SHU9119 into the DVC. Phasic blood pressure (top), heart rate (middle), and mean arterial pressure (bottom) are shown. This experiment was replicated in three more animals with similar results (see Results).
The results of the microinjection experiments also indicate that, in agreement with earlier reports (Petty and De Jong, 1982; Mosqueda-Garcia and Kunos, 1987), $\beta$-endorphin microinjected at a low dose into the DVC causes hypotension and bradycardia. Unlike the similar effects of $\alpha-\mathrm{MSH}$, these effects are mediated by naloxone-sensitive opiate receptors, which are most likely of the $\mu$-subtype (Mosqueda-Garcia and Kunos, 1987). Thus, activation of the neural pathway projecting from the arcuate nucleus to the ipsilateral DVC can produce cardiovascular depressor effects via release of more than one product of the same precursor, which interact with distinct receptors. The survival value of such an arrangement and the possibility that the relative amounts of $\alpha$-MSH and $\beta$-endorphin released may be regulated by differential processing remain to be tested.

In contrast to the cardiovascular depressor effects elicited in the DVC, intravenous injection of higher doses of MSH peptides has been reported to cause pressor and tachycardic effects (Callahan et al., 1985; 1988; Gruber and Callahan, 1989; Sun et al., 1992; De Wildt et al., 1993). Indeed, intravenous injection of melanocortins or some of their analogs was found to improve survival in experimental hemorrhagic shock (Bertolini et al., 1986). Findings to date also indicate that these effects are mediated indirectly via activation of sympathetic outflow to the heart and vasculature (Callahan et al., 1985) and therefore are likely to be of central origin. In the present experiments, $\gamma$-MSH was both more potent and efficacious in increasing blood pressure and heart rate via intracarotid as compared with intravenous administration, whereas $\alpha$-MSH was ineffective via either route. This has two important implications. First, the pressor and tachycardic effects are, most likely, generated at a central site of action. Because $\gamma$-MSH is a water-soluble peptide, it may act at sites outside the blood-brain barrier, such as certain circumventricular organs (Callahan et al., 1988), or it may act on the cerebral vasculature to cause hypoxic activation of sympathetic outflow (De Wildt et al., 1993). The second and potentially more important conclusion is that $\gamma$-MSH acts at an as yet unidentified melanocortin receptor. Of the five melanocortin receptors identified to date, the MC3-R has equal high affinity for $\alpha$-MSH and $\gamma$-MSH (Roselli-Rehfuss et al., 1993), whereas all of the other four receptors have high affinity for $\alpha$-MSH and much lower affinity for $\gamma$-MSH. Thus, the observed selectivity of $\gamma$-MSH for producing pressor and tachycardic effects and the lack of activity of $\alpha$-MSH does not match the pharmacological profile of any of the five melanocortin receptors. Furthermore, the heptapeptide $\mathrm{ACTH}(4-10)$ is known to have very low or no activity at either the MC4-R or the MC3-R (Adan et al., 1994; Mountjoy et al., 1994), whereas ACTH(4-10) is reasonably potent in eliciting pressor and tachycardic effects on intracarotid administration (Fig. 4). Finally, pretreatment with either SHU9119 or SHU9005 was unable to inhibit the pressor and tachycardic effects of $\gamma$-MSH, even when either was administered at a dose ratio of 10:1. In vitro studies of cells transfected with MC3-R yielded an $\mathrm{EC}_{50}$ value of $5 \mathrm{~nm}$ for $\gamma$-MSH to increase cAMP (Adan et al., 1994) and an antagonist $\mathrm{IC}_{50}$ value of $<5 \mathrm{nM}$ for SHU-9119 (Hruby et al., 1995) and $<10 \mathrm{~nm}$ for SHU9005 (Kesterson and Cone, unpublished observations). Thus, the involvement of MC3-R or MC4-R in the pressor and tachycardic effects of $\gamma$-MSH can be ruled out.

In summary, the present findings indicate at least two distinct central pathways of cardiovascular control by melanotropins, one involving the MC4-R in the medullary dorsal-vagal complex and the other an as yet unidentified melanocortin binding site that preferentially recognizes $\gamma$-MSH. Neural activation of MC4-R 

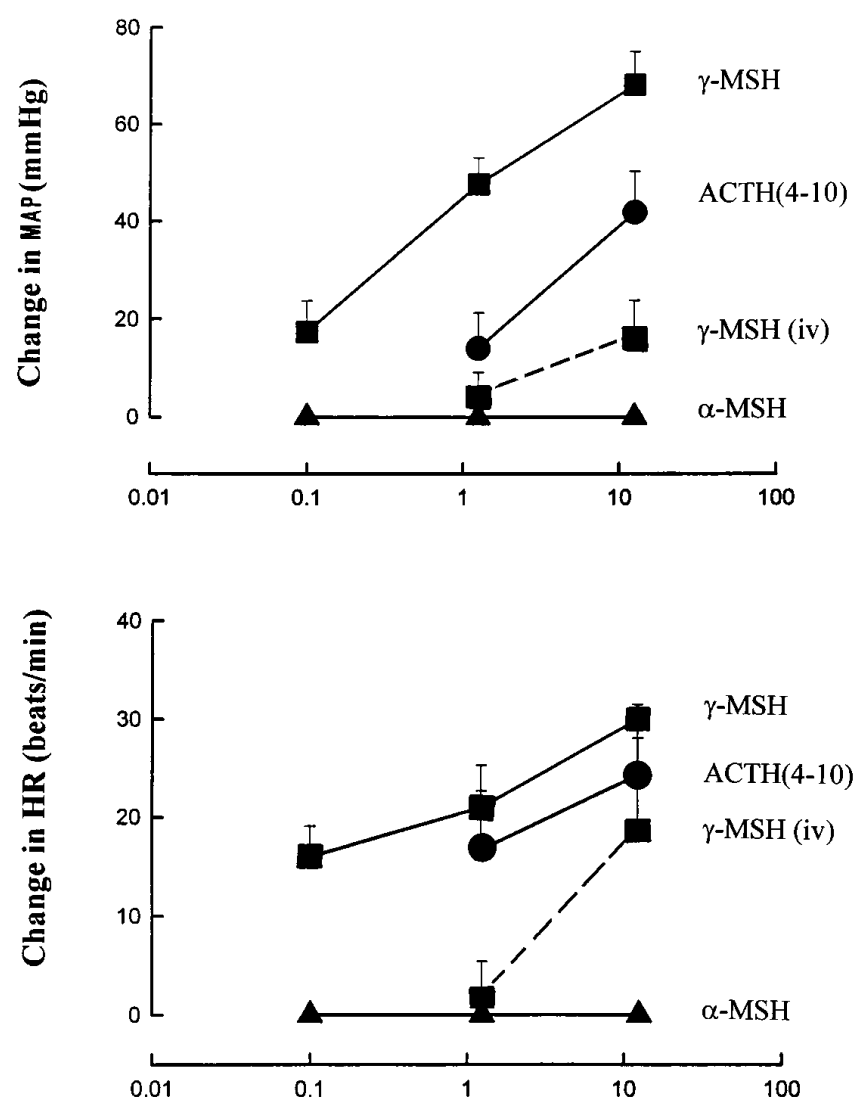

Dose (nmol)

Figure 4. The effects of intracarotid injections of $\gamma$-MSH, ACTH(4-10), and $\alpha$-MSH and of intravenous injection of $\gamma$-MSH on mean arterial blood pressure and heart rate in urethane-anesthetized rats. Mean \pm SE from 4-5 experiments is shown.

and possibly MC3-R in the dorsal medulla suggests a possible physiological role of $\alpha$-MSH in central cardiovascular regulation. The lack of involvement of these receptors in the pressor and tachycardic effects of $\gamma$-MSH suggests the existence of another, as yet unknown, melanocortin receptor in the brain or cerebral vasculature.

\section{REFERENCES}

Adan RAH, Cone RD, Burbach JPH, Gispen WH (1994) Differential effects of melanocortin peptides on neural melanocortin receptors. Mol Pharmacol 46:1182-1190.

Barnea A, Cho G, Pilotte NS, Porter JC (1981) Regional differences in the molecular weight profiles of corticotropin and $\alpha$-melanotropin in the hypothalamus. Endocrinology 108:150-156.

Bertolini A, Guarini S, Rompianesi E, Ferrari W (1986) $\alpha$-MSH and other ACTH fragments improve cardiovascular function and survival in experimental hemorrhagic shock. Eur J Pharmacol 130:19-26.

Bloom FE, Battenberg ELF, Shibasaki T, Benoit R, Ling N, Guillemin R (1980) Localization of $\gamma$-melanocyte-stimulating hormone $(\gamma \mathrm{MSH}) \mathrm{im}$ munoreactivity in rat brain and pituitary. Regul Pept 1:205-222.

Brody MJ, O'Neill TP, Porter JP (1986) Role of paraventricular and arcuate nuclei in cardiovascular regulation. In: Central and peripheral mechanisms of cardiovascular regulation (Magro A, Osswald W, Reis D, Vanhoutte P, eds), pp 443-464. New York: Plenum.

Callahan MF, Kirby RF, Wolff DW, Strandhoy JW, Lymangrover JR, Johnson AK, Gruber KA (1985) Sympathetic nervous system media- tion of acute cardiovascular actions of $\gamma_{2}$-melanocyte-stimulating hormone. Hypertension [Suppl I] 7:I145-I150.

Callahan MF, Cunningham JT, Kirby RF, Johnson AK, Gruber KA (1988) Role of the anteroventral third ventricle (AV3V) region of the rat brain in the pressor response to $\gamma_{2}$-melanocyte-stimulating hormone $\left(\gamma_{2} \mathrm{MSH}\right)$. Brain Res 444:177-180.

De Wied D, Jolles J (1982) Neuropeptides derived from pro-opiomelanocortin: behavioral, physiological, and neurochemical effects. Physiol Rev 62:976-1059.

De Wildt DJ, Krugers H, Kasbergen CM, De Lang H, Versteeg DHG (1993) The hemodynamic effects of $\gamma_{2}$-melanocyte-stimulating hormone and related melanotropins depend on arousal potential of the rat. Eur J Pharmacol 233:157-164.

De Wildt DJ, Van Der Ven JC, Van Bergen P, De Lang H, Versteeg DHG (1994) A hypotensive and bradycardic action of $\gamma_{2}$-melanocytestimulating hormone $\left(\gamma_{2}-\mathrm{MSH}\right)$ microinjected into the nucleus tractus solitarii of the rat. Naunyn Schriedebergs Arch Pharmacol 349:50-56.

Gantz I, Miwa H, Konda Y, Shimoto Y, Tashiro T, Watson SJ, DelValle J, Yamada T (1993) Molecular cloning, expression, and gene localization of a fourth melanocortin receptor. J Biol Chem 268:15174-15179.

Griffon N, Mignon V, Facchinetti P, Diaz J, Schwartz J-C, Sokoloff P (1994) Molecular cloning and characterization of the rat fifth melanocortin receptor. Biochem Biophys Res Commun 200:1007-1014.

Gruber KA, Callahan MF (1989) ACTH-(4-10) through $\gamma$-MSH: evidence for a new class of central autonomic nervous system-regulating peptides. Am J Physiol 257:R681-R694.

Hruby VJ, Lu D, Sharma SD, Castrucci A de L, Kesterson RA, Al-Obeidi FA, Hadley ME, Cone RD (1995) Cyclic lactam $\alpha$-melanotropin analogues of $\mathrm{Ac}-\mathrm{Nle}^{4}$-cyclo[Asp $\left.{ }^{5}, \mathrm{D}-\mathrm{Phe}^{7}, \mathrm{Lys}^{10}\right] \alpha$-melanocyte-stimulating hormone-(4-10)- $\mathrm{NH}_{2}$ with bulky aromatic amino acids at position 7 show high antagonist potency and selectivity at specific melanocortin receptors. J Med Chem 38:3454-3461.

Jacobowitz DM, O’Donohue TL (1978) $\alpha$-Melanocyte stimulating hormone: immunohistochemical identification and mapping in neurons of rat brain. Proc Natl Acad Sci USA 75:6300-6304.

Joseph SA, Pilcher WH, Knigge KM (1985) Anatomy of the corticotropin-releasing factor and opiomelanocortin systems of the brain. Fed Proc 44:100-107.

Kawai Y, Inagaki S, Shiosaka S, Shibasaki T, Ling N, Tohyama M, Shiotani Y (1984) The distribution and projection of $\gamma$-melanocytestimulating hormone in the rat brain: an immunohistochemical analysis. Brain Res 297:21-32.

Kunos G, Farsang C, Ramirez-Gonzalez MD (1981) $\beta$-Endorphin: possible involvement in the antihypertensive effect of central $\alpha$-receptor activation. Science 211:82-84.

Li S-J, Scanlon MN, Járai Z, Varga K, Gantenberg NS, Lazar-Wesley E, Kunos G (1996) $\alpha_{2}$-Adrenergic activation of pro-opiomelanocortin (POMC)-containing neurons in the arcuate nucleus causes opioidmediated hypotension and bradycardia. Neuroendocrinology 63:275-283.

Maggi CA, Meli A (1986) Suitability of urethane for physiopharmacological investigations in various systems. Experientia (Basel) 42:109-115.

Mastrianni JA, Palkovits M, Kunos G (1989) Activation of brainstem endorphinergic neurons causes cardiovascular depression and facilitates baroreflex bradycardia. Neuroscience 33:559-566.

Mezey E, Kiss JZ, Mueller GP, Eskay R, O'Donohue TL, Palkovits M (1985) Distribution of the pro-opiomelanocortin derived peptides, adrenocorticotrope hormone, $\alpha$-melanocyte-stimulating hormone, and $\beta$-endorphin (ACTH, $\alpha$-MSH, $\beta$-END) in the rat hypothalamus. Brain Res 328:341-347.

Mosqueda-Garcia R, Kunos G (1987) Opiate receptors and the endorphin-mediated cardiovascular effects of clonidine: evidence for hypertension-induced $\mu$-subtype to $\delta$-subtype changes. Proc Natl Acad Sci USA 84:8637-8641.

Mosqueda-Garcia R, Eskay R, Zamir N, Palkovits M, Kunos G (1986) Opioid-mediated effects of clonidine in spontaneously hypertensive rats: elimination by neonatal treatment with monosodium glutamate. Endocrinology 118:1814-1822.

Mountjoy KG, Robbins LS, Mortrud MT, Cone RD (1992) The cloning of a family of genes that encode the melanocortin receptors. Science 257:1248-1251.

Mountjoy KG, Mortrud MT, Low MJ, Simerly RB, Cone RD (1994) Localization of the melanocortin-4 receptor (MC4-R) in neuroendo- 
crine and autonomic control circuits in the brain. Mol Endocrinol 8:1298-1308.

O’Donohue TL, Handelman GE, Miller RL, Jacobowitz DM (1982) $\mathrm{N}$-acetylation regulates the behavioral activity of $\alpha$-melanotropin in a multitransmitter neuron. Science 215:1125-1127.

Osamura RY, Komatsu N, Watanabe K, Nakai Y, Tanaka I, Imura H (1982) Immunohistochemical localization of $\gamma$-melanocyte-stimulating hormone ( $\gamma$-MSH)-like immunoreactivity in human and rat hypothalamus. Peptides 3:781-787.

Palkovits M, Eskay RL (1987) Distribution and possible origin of $\beta$-endorphin and ACTH in discreet brainstem nuclei of rats. Neuropeptides 9:123-137.

Palkovits M, Mezey E, Eskay RL (1987) Pro-opiomelanocortin-derived peptides (ACTH $/ \beta$-endorphin $/ \alpha$-MSH) in brainstem baroreceptor areas of the rat. Brain Res 436:323-338.

Petty MA, De Jong W (1982) Cardiovascular effects of $\beta$-endorphin after microinjection into the nucleus tractus solitarii of the anesthetised rat. Eur J Pharmacol 81:449-457.

Roselli-Rehfuss L, Mountjoy KG, Robbins LS, Mortrud MT, Low MJ, Tatro JB, Entwistle ML, Simerly RB, Cone RD (1993) Identification of a receptor for $\gamma$-melanotropin and other pro-opiomelanocortin peptides in the hypothalamus and limbic system. Proc Natl Acad Sci USA 90:8856-8860.
Sim LJ, Joseph SA (1991) Arcuate nucleus projections to brainstem regions which modulate nociception. J Chem Neuroanat 4:91-109.

Sun XY, Feng QP, Gong QL, Edvinsson L, Hedner T (1992) Cardiovascular and renal effects of $\gamma$-MSH in spontaneously hypertensive and normotensive Wistar Kyoto rats. Am J Physiol 262:R77-R84.

Tatro JB, Entwistle ML (1993) Distribution of melanocortin receptors in the lower brainstem of the rat. Ann NY Acad Sci 680:311-314.

Umegaki K, Shiosaka S, Kawai Y, Shinoda K, Yagura A, Shibasaki T, Ling N, Tohyama M (1983) The distribution of $\alpha$-melanocyte-stimulating hormone $(\alpha-\mathrm{MSH})$ in the central nervous system of the rat: an immunohistochemical study. I. Forebrain and upper brain stem. Cell Mol Biol 29:377-386.

Van Giersbergen PLM, Roording P, de Lang H, de Jong W (1989) Participation of opiate receptors located in the nucleus tractus solitarii in the hypotension induced by $\alpha$-methyldopa. Brain Res 498:154-158.

Wiegant VM, Jolles J, Colbern DL, Zimmerman E, Gispen WH (1979) Intracerebroventricular ACTH activates the pituitary-adrenal system: dissociation from a behavioral response. Life Sci 25:1791-1796.

Yamazoe M, Shiosaka S, Shibasaki T, Ling T, Tateishi K, Hashimura E, Hamaoka T, Kimmel JR, Matsuo H, Tohyama M (1984) Distribution of six neuropeptides in the nucleus tractus solitarii of the rat: an immunohistochemical analysis. Neuroscience 13:1243-1266. 